\title{
Computer System for Electric Drives Fault Diagnosis of Mining Shovels
}

\author{
KashirskikhVeniamin G. ${ }^{1, a}$, Gargayev Andrey N. ${ }^{1, b}$, \\ Zavyalov Valeriy M. ${ }^{2}$, Semykina Irina Y. ${ }^{1, c}$ \\ ${ }^{1}$ T. F. Gorbachev Kuzbass State Technical University \\ Kemerovo, Russian Federation \\ ${ }^{2}$ National research Tomsk polytechnic university, Tomsk, Russian Federation \\ 1,a kvg.ea@kuzstu.ru; ${ }^{1, b}$ andrei345@yandex.ru; ${ }^{2}$ zavyalov@tpu.ru; ${ }^{1, c}$ siyu.eav@ kuzstu.ru
}

\begin{abstract}
It is proposed to conduct fault diagnostic test on electric drives of mining shovels based on the results of monitoring the current values of electromagnetic and mechanical parameters and variables of electric drives obtained in the course of their operation using the modern computer technology. The structure of the developed system of functional diagnostics, allowing to monitor the status of the drive and identify emerging fault is shown in the paper. To determine in real time the current parameters and variables of DC motor which can't be measured during their operation, the dynamic identification was used based on the measured current and voltage of the motor windings, and mathematical estimation methods. Parameters of the mechanical subsystem of electric drive are identified by a mobile measuring system. The authors also give the structure and characteristics of the one-step neural network predictor of current, used to predict the current values in the armature and field windings of motor. The analysis of the technical state of the electric drive by a set of attributes is performed in a special analyzer, built on the basis of pre-trained artificial neural network. The results of these studies support the possibility of creating a diagnostic system for the main electric drives of mining shovels using the estimation methods and apparatus of artificial neural networks.
\end{abstract}

Keywords - electric drive; DC motor; diagnosis; dynamic identification; estimation; predictor; artificial neural network.

\section{INTRODUCTION}

A large number of failures causing emergency shutdowns of mining shovels refer to the faults of main electric drives. To improve the situation, the maintenance system of electric drives should transfer to the condition monitored maintenance [1]. Thus, there is a need for continuous monitoring of the parameters, determining technical state of the electric drive, and using the data obtained for the fault diagnosis [2].

Currently, there exists quite a variety of diagnostic tools [3-13]. However, the available electric drive diagnostic systems of mining shovels are limited, mainly, to control of such parameters as oil level, bearing temperature, vibration, current of the armature and field windings, position of the shovel, its tilt angle, and others [14]. At the same time, electromagnetic processes in electrical machines and dynamic processes in mechanical subsystem of electric drive are not analyzed, although these data can be used for electric drives diagnosis. This approach, together with the existing diagnostic tools, will allow creating an integrated universal diagnostic system in order to control the required parameters and alarm in the case of fault.

\section{SUBJECT OF RESEARCH}

The set of the main electric drives of mining shovels is a complex system, which includes electrical, electromechanical and mechanical converters integrated by the control system, as well as power and data channels. In our opinion, for the electric drives fault diagnosis (equipment on-the-run) it is necessary to carry out continuous monitoring of parameters and their subsequent processing. For this purpose, it is required to use a set of sensors, software and hardware, including a computer, interface units and customized software. Thus, the obtained real time data is the basis for diagnostic algorithms implementation using artificial intelligence methods as well.

However, not all the parameters identifying the technical state of an electric drive can be directly measured during its operation. For example, in DC motors we can't directly measure such parameters as active resistance and inductance of the armature and field windings, mutual inductance of windings, etc. These data can be obtained in an indirect way, using the procedures of dynamic identification based on mathematical estimation methods [15]. The measured current and voltage of windings as well as the mathematical model of the motor can be used as the initial data.

\section{MATERIALS AND METHODS}

Fig. 1 shows the structure of proposed electric drive diagnostic system with data mining modules. For the electric drive containing a DC motor, an electrical converter with a control system and a mechanical subsystem, the monitoring devices were designed for electromagnetic and mechanical variables, predictors, as well as the technical state's analyzers. Here X, Y are respectively, the vectors of input and output signals of DC motors, and $\beta \mathrm{e}, \beta \mathrm{m}$ are their estimations. This structure of the diagnostic system is shown only for one of the main electric drives of a mining shovels, the structure will be similar for the rest of them. 


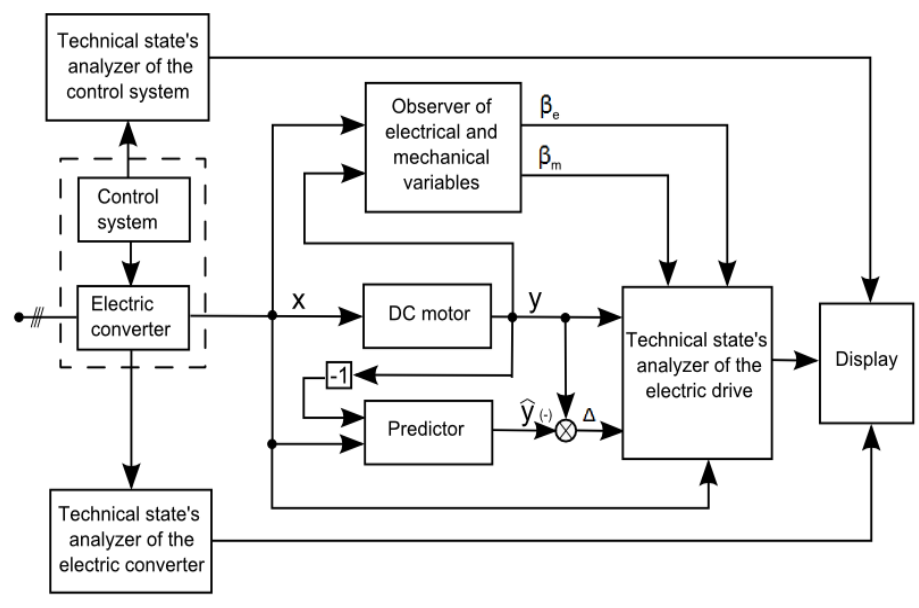

Figure 1 - Diagnostic system structure

Monitoring devices are designed for real-time estimation of electromagnetic and mechanical variables of electric drives using the computer analysis of the data in the measured signals of current, voltage, speed and angular movements. To predict the values of the output vector of DC motor state $(\hat{y})$ by its history one step ahead, it is possible to use a predictor built on the basis of the artificial neural network (ANN). These estimates ( $\beta \mathrm{em}, \beta \mathrm{m})$, current and voltage of DC motor windings, as well as the error between an output signal of the neural predictor and the actual measured current $(\Delta)$ enter the technical state's analyzer which processes the received data, recognizes the technical state of the operating electric drive by a number of features and displays the result data.

The main elements of the electric drives creating the flows of mechanical energy to destruct and displace rock mass, and move the mining machines are electric motors. Their dynamic state is greatly affected by the processes, occurring in the other elements of the drive, so when developing a fault diagnostic system they should be given a special attention. During the identification we used the equations, derived from the generalized electric machine theory $[16,17]$ as a mathematical model of DC motor:

$$
\begin{aligned}
& U_{\mathrm{f}}=i_{\mathrm{f}} \cdot R_{\mathrm{f}}+L_{\mathrm{f}} \cdot \frac{d i_{\mathrm{f}}}{d t} ; \\
& U_{\mathrm{a}}=i_{\mathrm{a}} \cdot R_{\mathrm{a} \Sigma}+L_{\mathrm{a} \Sigma} \cdot \frac{d i_{\mathrm{a}}}{d t}+p \cdot L_{12} \cdot \omega \cdot i_{f} ; \\
& J \cdot \frac{d \omega}{d t}=T_{m}-T_{l} \\
& T_{m}=p \cdot L_{12} \cdot i_{f} \cdot i_{a},
\end{aligned}
$$

where $U_{a}, U_{f} ; i_{a}, i_{f} ; L_{a \Sigma}, L_{f} ; R_{a \Sigma}, R_{f}$ - respectively, supply voltage, current, inductance and active resistance of the armature and field windings; - angular velocity of the armature rotation; - inertia moment; - electromagnetic torque; - resistance torque; - number of pole pairs.

To date, there are many scientific publications devoted to identification of the parameters and state of a DC motor. Review of the literature sources showed that the most frequently used estimation methods are as follows:
1. The least-square and recursive least-square methods. They are about minimizing the integrated square error of identification by RMS criteria [18,19].

2. Kalman Filter, which allows the dynamic identification of the subject parameters with the known structure of its dynamic model under the conditions of incomplete and noisy data. Kalman filter is widely used as it allows estimating not only parameters but also system state in real time [20,21].

3. Search Methods. Search for parameters of DC motor model is performed based on a specific algorithm, writing to memory the results with minimal identification error [22].

4. Genetic algorithms - search algorithms that resemble biological evolution, in which the search for solutions is performed by random selection, combination and variation of desired parameters [23-27].

5. Artificial Neural Network is a mathematical model of interconnected artificial neurons, having as a whole the capacity for learning [28,29].

To test the efficiency of these methods, we have developed the software conducting computer simulations for a number of DC motors. The results of the simulations are as follows [3033]:

- All of the above methods can be used for dynamic identification of DC motors;

- Estimation of parameters and state of DC motor in real time by all of these methods is performed with an error permissible for practical use - no more than $15 \%$;

- To use estimation methods based on mathematical models of DC motor, it is necessary and sufficient to possess the data of present voltage and current of the armature and field windings, and in some cases it is also necessary to measure the angular velocity of DC motor.

To determine the relationship between electromagnetic parameters of a DC motor and its technical state, we conducted theoretical and laboratory research of DC motors, operating in normal and most common emergency modes. When setting the faults, we detected particular changes in the electrical parameters of DC motor derived from dynamic identification.

To monitor the state of the electric drive mechanical subsystem of the mining shovel, a mobile measuring system was designed [31] which carried out synchronous measurement of drive motors current and angular positions of the winch drums, jib-head pulley, and crawling engine. To improve the efficiency of assembly and disassembly of the measuring system, the position sensors were installed by means of permanent magnets. Measuring system sensors are schematically shown in Fig. 2. The measuring system includes: position measuring units (1-4), current measuring units $(5,6)$, base station (7), personal computer (8) and radio module. Since the sensors are installed separately in space, data from the sensors to the base station are transferred by radio channel. 
When setting a signal from the base station to the measuring units, located on the drums and armature circuits of motors, the latter starts to measure the relevant variables. In each measurement cycle the data are processed by microcontrollers and simultaneously written to memory. Angular positions were measured using specially designed sensors, made on the basis of accelerometers Figure 2.

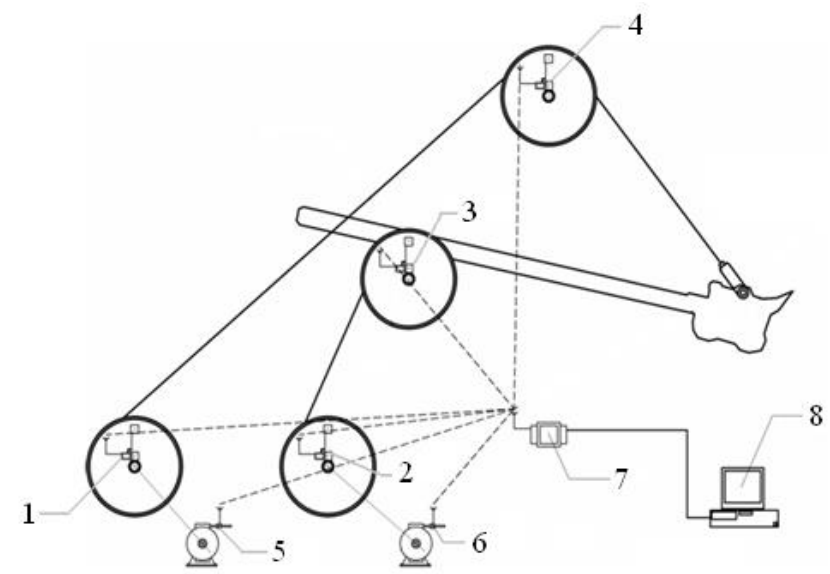

Figure 2 - Sensors installation on the mining shovel.

\section{FINDINGS AND DISCUSSION}

When testing a mobile measuring system on electric drives of the mining shovel EKG-10 (Vakhrushevsky coal mine in the Kuzbass region) the data were obtained on the state of angular velocities of winch drums, jib-head pulley and crawling engine, electromagnetic torque of the motor, and stress in the ropes. Some results obtained during the tests are shown in Fig. 3. Mobile measuring system enables monitoring dynamic state of the mechanical elements of electric drives of mining shovel and, on the basis of the data, identifying the stress in the ropes. The result data are transferred to the diagnostic system.

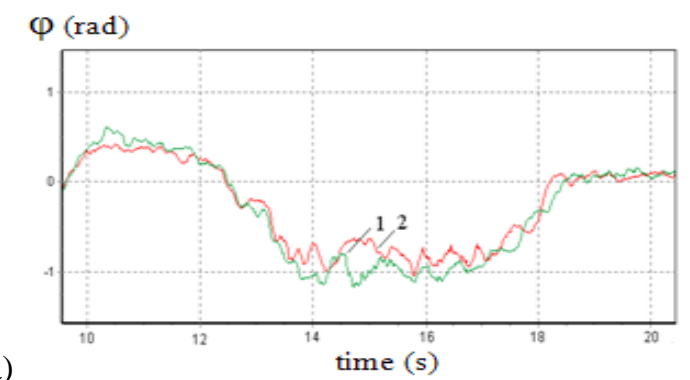

a)

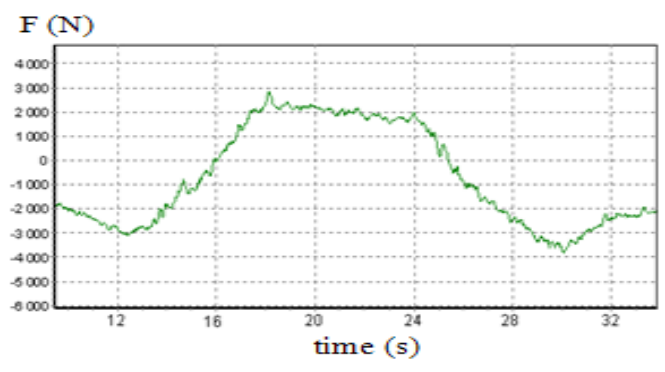

Figure 3 - Test results: a) angular positions of winch drum (1) jib-head pulley (2) crawling engine; b) stress in the rope of crawling engine

To carry out diagnosis procedures, we developed the neural network predictor (Fig. 4), as a computer model based on ANN, predicting the output vector of subject state by its history one step ahead. For this purpose, predictor must be trained on the data received from the fault-free motor when operating in different dynamic modes. When training, the neural network approximates the functional relationship between the input (X) and output (Y) signals.

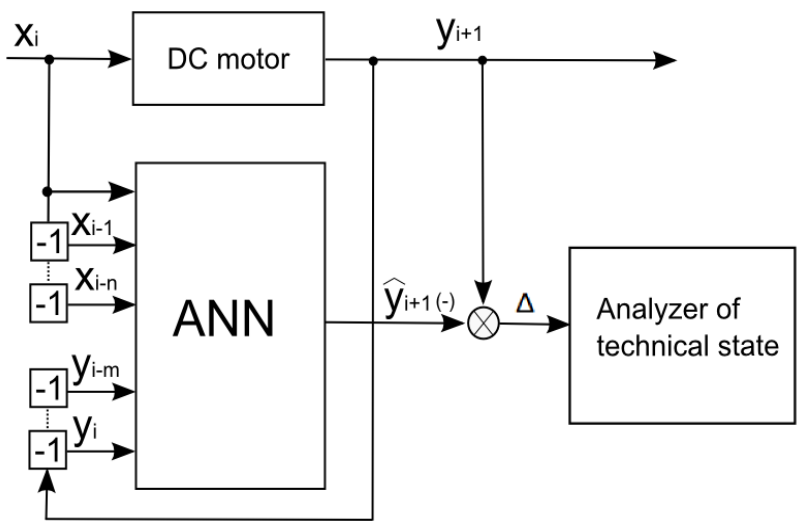

Figure 4 - Flow chart of neural predictor

As input signals we used voltage in windings, angular velocity, resistance torque, as well as output signal delayed by a certain time. The time delay is determined by the subject dynamics, in this case it equals $1 \mathrm{~ms}$. The output signal predicted one step ahead electric current in winding. Accuracy of prediction depends on the parameters, training time, volume and quality of the training sample.

When fault-free motor output signal of the predictor is almost equal to the actual measured current, the error is insignificant (Figure 5). In case of a fault, predictor signal does not coincide with the motor current which leads to error. Fig. 6 shows the predictor signals and the motor current, as well as the error when brushes are displaced from the geometrical neutral. Based on the ratio and sign of error, as well as time rate of the error ratio can be diagnosed the technical state of DC motor.

A set of experiments showed that DC motor windings continuity causes positive error between the predictor output signal and the actual measured motor current, but fault leads to the negative error. The error ratio depends on the degree of fault, e.g. the more commutator bars are faulty, the more significant is the error. Analysis of the results confirmed the possibility of using neural predictor error for diagnosis purposes. However, predictor operates adequately only for this type of motor, and needs additional training to diagnose other types of motors.

The procedure of motor diagnosis can be attributed to the problem of classification when determining the relation of input set of diagnostic data to one of several known classes of motor technical state. To analyze the data derived from the monitoring devices and current predictors, and to determine the technical state of electric drive, the technical state's 
analyzer was designed using artificial neural network (Fig. 7) which is one of the most efficient and proven tools for solving classification problems [33].

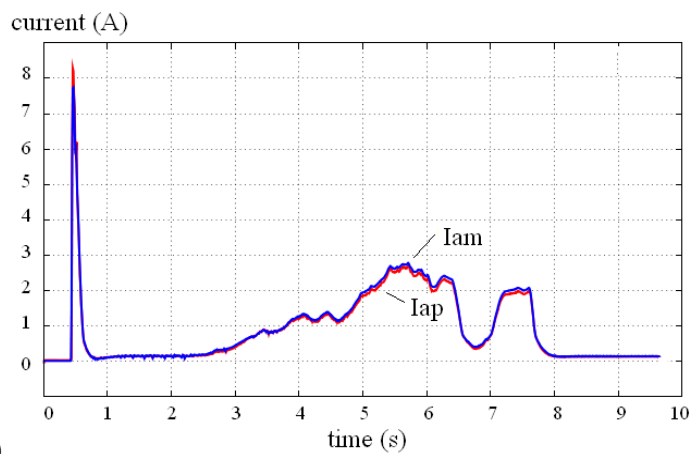

a)

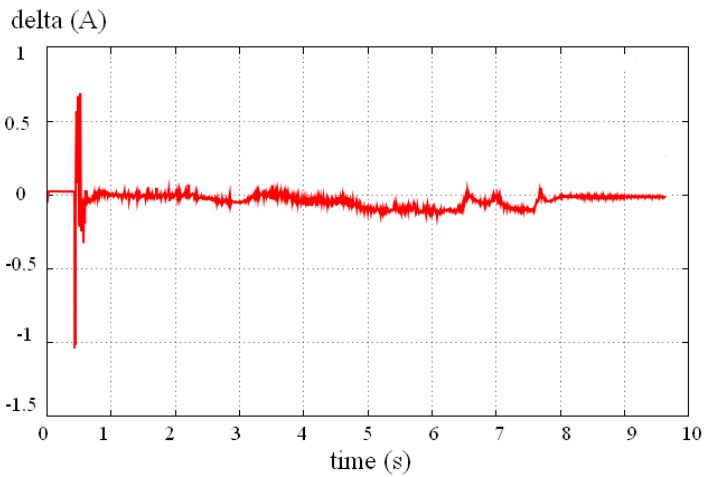

Figure 5 - Test results:

a) Iam - measured armature current, Iap - predictor output signal, b) delta - signals error

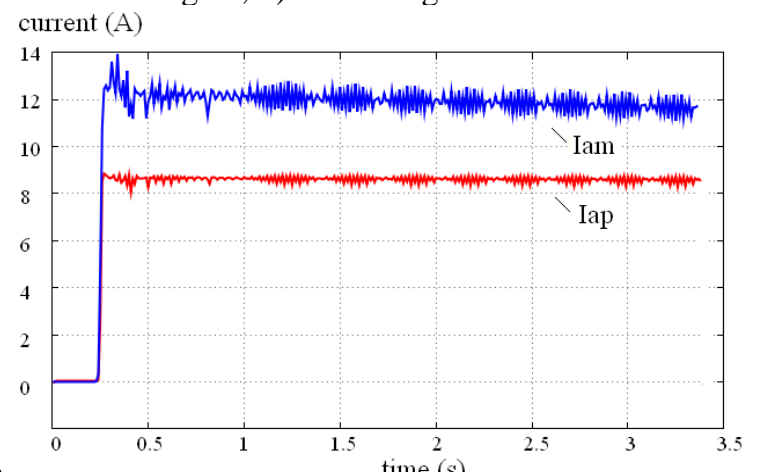

a)

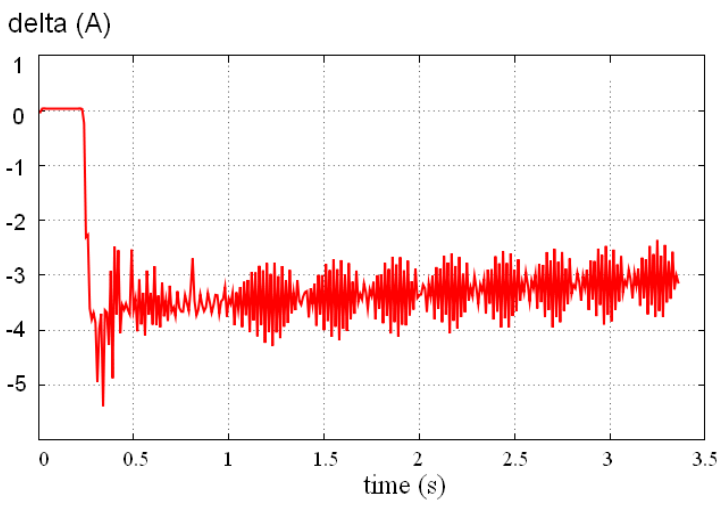

b)

Figure 6 - Test results: a) Iam - measured armature current under commutator bar fault; Iap - predictor output signal; b) delta - signals error

The neural network approximates nonlinear relationship and resists noises in the training data. As ANN structure a multilayer perceptron-based network was chosen with one hidden layer, which is relevant for solving classification problems. Number of input layer neurons was determined by the amount of diagnostic features, the output layer - by the number of diagnosed technical states.

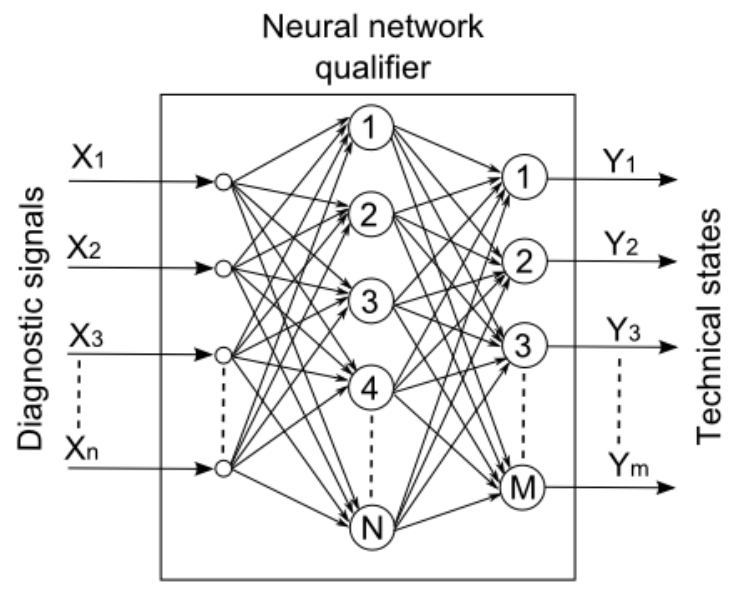

Figure 7 - Structure of technical state's neural analyzer

The concept of ANN training is training with an educator. Based on embedded knowledge, the educator generates and transfers a desired response for each set of input signals to the trained neural network. These desired results should be selected by the neural network in the process of self-study. After training procedures the educator is disconnected. During the training an error backpropagation algorithm was used; herewith, the synaptic weights were selected with the aim of maximum approximation of output signal to the desired one. As activation function an exponential sigmoid was assumed that meets the requirement of function differentiability.

Input signals for neural analyzer are the data obtained for DC motor and mechanical subsystem by measurement and estimation. Output signals are certain classes of electric drive technical state. To create the training sample, we used the data derived from laboratory tests of DC motor type P-12. Within the motor, operating in different dynamic modes, were artificially created typical failures - continuity and faults of armature and field windings, locking and others. We created the database of measurements and, corresponding to these measurements, technical states of DC motor. As a result, the volume of training sample made 35,000 specimens, including periods of training equal to 100000 . Training sample for the mechanical subsystem was created using the results obtained during the mobile measuring system tests under plant conditions.

For the actual electric drives of mining shovels, neural network must be trained at the specialized work benches of manufacturers or industrial plants before involving mining 
shovels into the process. Herewith, an important feature of the diagnostic system based on neural network is a possibility to expand diagnosed classes of emergency modes by additional ANN training. This diagnostic system also allows the expansion of its functional properties through the use of additional signals, such as motor temperature, level of brush sparking, vibration and others. This allows creating a diagnostic system for the specific technical needs of the customer.

In addition, the considered approach can be used for the development of the diagnostic system of AC drives. For these purposes algorithms and software for dynamic identification of AC motors were developed at the Department of electric drive and automation of Kuzbass State University,.

\section{CONCLUSION}

To sum up, the development and application of diagnostic systems using intellectualization of diagnostic data processing makes it possible to detect faults of electric drives of mining shovels at early stages, to reduce the time and material costs for troubleshooting. This will allow the maintenance system to cross over to the condition monitored maintenance and thereby to improve the reliability and efficiency of mining shovels.

\section{REFERENCES}

[1] DroshevYu.S. Povysheniye tekhnologicheskoy nadezhnosti kar'yernykh ekskavatorov [Increase in technological reliability of mining shovels]. Yu.S. Droshev, S.B. Nestrugin. Vladivostok: Publishing House DVGTU, 2009. 194 p.

[2] Gerike B.L. Diagnostika gornykh mashin i oborudovaniya [Diagnosis of mining machinery and equipment]. B.L. Gerike, A.A. Khoreshok, P.B. Gerike. Kemerovo: KuzGTU, 2012. 310 p

[3] Lyakhomskiy A.V. Metod poiska neispravnosti ili otkaza glavnykh elektroprivodov kar'yernykh ekskavatorov [Method of search for malfunction or failure of the main electric drives of mining shovels]. A.V. Lyakhomskiy, I.M. Khoshmukhamedov. Elektrika. 2006. No. 7. pp. 33-35.

[4] Khoshmukhamedov I.M. Diagnosticheskiye priznaki I metody elektrosilovogo diagnostirovaniya oborudovaniya gornykh mashin [Diagnostic features and methods of electric power diagnosis for mining machinery]. I.M. Khoshmukhamedov, O.V. Kosarev-Volod'ko. Elektrika. 2007. No. 4. pp. 33-35.

[5] Dietmar Benda. Poisk neispravnostey v elektricheskikh skhemakh [Troubleshooting in electrical circuits]. SPb. BHV-Petersburg, 2010. 256 p.

[6] Glinka T.Ya. Diagnostirovaniye izolyatsiy obmotok elektricheskikh mashin postoyannogo toka [Diagnosis of windings insulation of DC electrical machines]. T.Ya. Glinka, M.S. Yakubets. Elektrotekhnika. 2005. No. 7. pp. 20-24.

[7] Sposob diagnostiki kommutatsii obmotok yakorya I kachestva pitaniya kollektornykh elektrodvigateley postoyannogo toka [Method for switching diagnosis of armature windings and supply quality of DC commutator motors]. Patentnumber 2362177 G01R31/06 Russia. A.I. Prygunov. Publ. 20.07.2009

[8] Petukhov V.S. Diagnostika elektrodvigateley. Spektral'nyy analiz moduley vektorov parka toka i napryazheniya [Diagnosis of electric drives. Spectral analysis of Park's vector modules of current and voltage]. NovostiElektroTekhniki. 2008. No.1 (49)

[9] Todd D. Analysis of Brushed DC Machinery Faults With CoupledFinite Element Method and Equivalent Circuit Model / D. Todd, Batzel,
Nicholas C. Becker, M. Comanescu // 2011 IAJC-ASEE International Conference, Paper 024, ENG 106

[10] Manana M. Field winding fault diagnosis in DC motors during manufacturing using thermal monitoring / M. Manana, A. Arroyo, A Ortiz, C.J. Renedo, S. Perez, F. Delgado // Applied Thermal Engineering / Volume 31, Issue 5, April 2011, P. 978-983

[11] Iorgulescu M. Study of DC motor diagnosis based on the vibration spectrum and current analysis / M. Iorgulescu, R. Beloiu // Applied and Theoretical Electricity (ICATE), 2012 International Conference on, p.1 4

[12] Boltezar M. Fault Detection of DC Electric Motors Using the Bispectral Analysis / M. Boltezar, J. Slavi // Springer 2006, Meccanica (2006) 41: 283-297

[13] CheSoh A. Fault Detection and Diagnosis for DC Motor in Robot Movement System using Neural Network / A. CheSoh, R.Z. Abdul Rahman // The Pacific Journal of Science and Technology, Volume 10. Number 1. May 2009 (Spring), p.35-42.

[14] Jean-Claude Trigeassou. Electrical Machines Diagnosis // WILEY 2011

[15] Radojka K., Sanja A., Danilo S. Recursive Least Squares Method in Parameters Identification of DC Motors Models, [text] // FACTA UNIVERSITATIS, SER.: ELEC. ENERG. December 2005. - vol. 18 , no. 3 , P. 467-478

[16] Mohammed S. Z. Salah. Parameters identification of a permanent magnet dc motor [text] // The Islamic University of Gaza, 2009. - 94 c.

[17] VijaylakshmiJigajinni S. Simulation of Incipient Fault Detection, Confirmation and Diagnosis Using Kalman Filter // International Journal of Science and Research, Volume 3 Issue 8, August 2014, p.1846-1850

[18] WEI Tong. Application of adaptive Kalman filtering in system identification of brushless DC motor // WEI Tong,Rui GUO / Editorial Office of Optics and Precision Engineering, 08 August 2012

[19] Udomsuk, K-L. Areerak, K-N. Areerak and A. Srikaew. Parameters Identification of Separately Excited DC Motor using Adaptive Tabu Search Technique [text] // Sch. of Electr. Eng., Suranaree Univ. of Techonology (SUT), NakhonRatchasima, Thailand, 20 June 2010. - vol. $48-51$

[20] Alireza REZAZADEH. Genetic Algorithm based Servo System Parameter Estimation during Transients [text] // Department of Electrical and Computer Engineering, ShahidBeheshti University, G. C, Evin, Tehran, 2010.- vol 10, no 2.

[21] M. Lankarany, A. Rezazade Parameter estimation optimization based on genetic algorithm applied to dc motor [text] // IEEE International Conf. on Electrical Engineering. (ICEE), 2007. P.1-6

[22] Dupuis A., Ghribi M., Kaddouri A. Multiobjective Genetic Estimation of DC Motor Parameters and Load Torque [text] // IEEE International Conf. on Ind. Tech. (ICIT), 2004. P.1511-1514.

[23] JuggrapongTreetrong. Electric motor fault diagnosis based on parameter estimation approach using genetic algorithm, Proceedings of the international muticonference of engineers and computer scientists 2010

[24] S. Cong, X. Feng, Parameters Identification of DC Motor Based on GA and Simplex Method [text] // Control Engineering of China, 2009. - vol. 16, no. 1, P.09-112

[25] Arif A. AL-Qassar, Mazin Z. Othman. Experimental determination of electrical and mechanical parameters of dc motor using genetic elman neural network [text] // Journal of Engineering Science and Technology, 2008.- vol. 3, no. 2. P. $190-196$

[26] Feilat E. A., Maaitah E.K. Identification and control of DC motors using RBF neural network approach [text] // International conference on communication, computer and power, February $15-18$, 2009, C. 258 264.

[27] Gargayev A.N. Diagnostika elektroprivodov kar'yernykh ekskavatorov na osnove dinamicheskoy identifikatsii elektrodvigateley [Diagnosis of electric drives of mining shovels using electric motor dynamic identification]. Ph.D thesis. Kemerovo. 2013. 161 p.

[28] Gargayev A.N. Primeneniye fil'tra Kalmana dlya dinamicheskoy identifikatsii dvigateley postoyannogo toka [Application of Kalman filter for dynamic identification of DC motors] A.N. Gargayev, V.G. Kashirskikh. Vestn. KuzGTU. 2013. No. 1. pp. 131-134 
[29] Kashirskikh V.G. Diagnostika dvigateley postoyannogo toka s pomoshch'yu iskusstvennoy neyronnoy seti [Diagnosis of DC motors using artificial neural network]. V.G. Kashirskikh, A.N. Gargayev. Vestnik KuzGTU. 2014. No. 2. pp. 104-106.

[30] Gargayev A.N. Identifikatsiya parametrov dvigateley postoyannogo toka s pomoshch'yu metoda roya chastits [Parameters identification of DC motor using particle swarm]. A.N. Gargayev, V.G. Kashirskikh. Vestnik KuzGTU. 2015. No. 4. pp. 71-75.
[31] Gargayev A.N. Sistema monitoringa dinamicheskogo sostoyaniya elektroprivodov kar'yernykh ekskavatorov [Monitoring system of dynamic state of mining shovels]. V.M. Zavyalov, A.P. Noskov, V.S. Gorodnyanskiy, A.N. Gargayev. Vestnik KuzGTU. 2009. No. 3. pp 5962.

[32] Haykin S. Neural networks a comprehensive foundation. [Neural networks: a complete course. 2nd edition]. Moscow. Publishing house "Williams". 2006. 1104 